\title{
SISTEM PENDUKUNG KEPUTUSAN PEMILIHAN KEGIATAN \\ EKSTRAKURIKULER UNTUK SISWA SMA MENGGUNAKAN METODE SIMPLE MULTI ATTRIBUTE RATING TECHNIQUE (STUDI KASUS : SMA SANTA MARIA CIREBON)
}

\author{
Septian Galuh Andika ${ }^{1}$, Kusnadi $^{2}$, Petrus Sokibi ${ }^{3}$ \\ Sekolah Tinggi Manajemen Informatika dan Komputer CIC Cirebon \\ Jln. Kesambi 202, Kota Cirebon, Jawa Barat. Telp.(0231) 220250 \\ E-Mail : septiangaluh.andi@gmail.com,kusnadi@cic.ac.id, petrus.sokibi@cic.ac.id
}

\begin{abstract}
Kegiatan ekstrakurikuler merupakan suatu bagian internal dari proses belajar yang menekankan pada kebutuhan siswa di luar kegiatan belajar mengajar di SMA Santa Maria Cirebon. Banyaknya kegiatan ekstrakurikuler yang ada membuat siswa sulit untuk menentukan kegiatan ekstrakurikuler yang akan diikuti, sehingga tidak jarang siswa tersebut salah memilih ekstrakurikuler dan tidak sesuai dengan potensi yang mereka miliki. Salah satu solusi untuk membantu para siswa dalam memilih kegiatan ekstrakurikuler adalah dengan menggunakan sistem pendukung keputusan pemilihan kegiatan ekstrakurikuler. Metode Simple Multi Atribute Rating Technique (SMART) merupakan metode yang dalam penerapannya mempertimbangkan beberapa kriteria dan alternatif yang mampu membantu pengguna dalam menentukan pilihannya dengan lebih tepat sehingga dapat digunakan dalam sistem penunjang keputusan.Dengan adanya sistem pendukung keputusan pemilihan kegiatan ekstrakurikuler ini diharapkan dapat membantu sekolah dalam mengolah data dan mendapatkan data dengan efisien karna sistem ini menyimpan data secara terpusat serta terorganisir.
\end{abstract}

Kata Kunci : Ekstrakurikuler, SMART, Sistem Pendukung Keputusan

\begin{abstract}
Abstrak
Extracurricular activities are an internal part of the learning process that emphasizes the needs of students outside of teaching and learning activities at Santa Maria Cirebon High School. The number of extracurricular activities that exist make it difficult for students to determine extracurricular activities that will be followed, so it is not uncommon for these students to choose extracurricular activities and not according to their potential. One solution to assist students in choosing extracurricular activities is to use a decision support system for selecting extracurricular activities. The Simple Multi Attribute Rating Technique (SMART) method is a method that in its application considers several criteria and alternatives that are able to assist users in making their choices more precisely so that they can be used in decision support systems. With the existence of a decision support system the selection of extracurricular activities is expected to help schools in processing data and obtain data efficiently because this system stores data centrally and organized.
\end{abstract}

Keyword : Extracurricular, SMART, Decision Support System

JURNAL DIGIT Vol. 9, No.1 Mei 2019 : 59-70 


\section{Pendahuluan}

Pada saat ini teknologi yang berkaitan dengan teknologi komputer semakin berkembang cepat dan semakin canggih. Dimana teknologi komputer merupakan pendukung kemajuan teknologi informasi sangat berpengaruh kepada perkembangan hal di segala bidang seperti bisnis, pendidikan, kehidupan sosial, kesehatan, politik, perekonomian dan lain-lain. Peranan sistem teknologi informasi juga sangat mendukung pengolahan data dalam suatu perusahaan, organisasi, lembaga, atau instansi dengan maksud untuk mempermudah mendapatkan informasi yang relevan, akurat, dan tepat waktu.SMA Santa Maria Cirebon adalah salah satu Sekolah Menengah Atas Swasta di Kota Cirebon yang selalu berupaya memunculkan dan mengembangkan potensi yang dimiliki siswanya tidak hanya melalui kegiatan akademis namun juga dari kegiatan non akademis. Salah satu upaya yang dilakukan adalah dengan meningkatkan kegiatan ekstrakurikuler bagi para siswa. Kegiatan ekstrakurikuler tersebut sejalan dengan Pasal 3 Undang-Undang Nomor 20 Tahun 2003 tentang Sistem Pendidikan Nasional yang menyebutkan bahwa pendidikan nasional bertujuan untuk berkembangnya potensi peserta didik agar menjadi manusia yang beriman dan bertakwa kepada Tuhan Yang Maha Esa, berakhlak mulia, sehat, berilmu, cakap, kreatif, mandiri, dan menjadi warga negara yang demokratis serta bertanggung jawab. Pengembangan potensi peserta didik sebagaimana dimaksud dalam tujuan pendidikan nasional tersebut dapat diwujudkan melalui kegiatan ekstrakurikuler

Proses pemilihan kegiatan ekstrakurikuler oleh para siswa di SMA Santa Maria Cirebon masih dilakukan secara manual, dengan cara siswa mengisi formulir pendaftaran ekstrakurikuler yang dibagikan oleh bagian kesiswaan. Formulir yang dibagikan kepada siswa berisi biodata siswa serta pilihan ekstrakurikuler yang tersedia. Setelah formulir terisi kemudian dikumpulkan ke ketua kelas untuk diberikan kepada bagian kesiswaan. Mekanisme pengisian formulir dengan cara tersebut dinilai tidak efektif dan menimbulkan beberapa permasalahan seperti hilangnya formulir pemilihan, formulir tidak tersalurkan ke semua siswa, beberapa siswa tidak memilih kegiatan ekstrakurikuler karena tidak adanya pemeriksaan oleh bagian kesiswaan, siswa salah memilih kegiatan ekstrakurikuler yang tidak sesuai karakternya dan siswa yang tidak berada di sekolah pada saat pemilihan tidak dapat memilih kegiatan ekstrakurikuler.

Simple Multi Attribute Rating Technique(SMART) yaitu merupakan suatu metode untuk pengambilan keputusan multi kriteria yang dikembangkan pada tahun 1997 oleh Edward. Metode SMART didasarkan pada teori bahwa setiap alternatif terdiri dari sejumlah kriteria yang memiliki bobot yang menggambarkan seberapa penting nilai dari bobot tersebut dengan kriteria lain. Menurut Jurnal Veti Apriana berjudul penerapan metode $A H P$ untuk pemilihan ekstrakurikuler pada siswa sekolah menengah kejuruan terbitan Maret 2017 menjelaskan perlunya penulis dalam membuat penelitian ini karena siswa masih sulit menentukan kegiatan ekstrakurikuler yang relatih banyak, penulis menerapkan metode $A H P$ untuk pemilihan kegiatan ekstrakurikuler yang dirasa cukup efektif dalam menyederhanakan dan mempercepat proses pengambilan keputusan dengan memecahkan persoalan tersebut ke dalam bagian-bagiannya (sistematis dan terstruktur), namun setelah membaca jurnal tersebut saya menyimpulkan bahwa metode $A H P$ sudah memiliki cara yang sistematis dan terstruktur tetapi metode $A H P$ memiliki ketergantungan pada input utamanya yang berupa persepsi para ahli dan metode AHP menjadi tidak berguna jika ahli tersebut memberikan penilaian yang keliru. Metode lain yang dapat digunakan untuk permasalahan tersebut adalah metode SMART. Penggunaan metode SMART dalam penelitian saya karena saya melihat bahwa metode SMART lebih sederhana dan sesuai dengan kajian penelitian yang penulis lakukan. Selain itu metode ini juga lebih mudah untuk diterapkan karena tidak memerlukan pemahaman matematika yang kuat, perhitungan pembobotan pada setiap alternatif agar terpilihlah alternatif terbaik, penetapan bobot untuk setiap kriteria dalam urutan kepentingan mudah dimengerti dan relatif efisien karna hanya membutuhkan satu keputusan yang harus dibuat per alternatif dan kriteria.

Berdasarkan uraian dan penjelasan di atas maka penulis tertarik untuk memecahkan permasalahan pemilihan kegiatan ekstrakurikuler di SMA Santa Maria Cirebon yang berjudul "Sistem Pendukung Keputusan Pemilihan Kegiatan Ekstrakurikuler untuk Siswa SMA Menggunakan Metode Simple Multi Attribute Rating Technique". 


\section{Kajian Pustaka}

\section{A. Multi Criteria Decision Making (MCDM)}

Multi Criteria Decision Making (MCDM) adalah suatu metode pengambilan keputusan untuk menetapkan alternatif terbaik dari sejumlah alternatif berdasarkan beberapa kriteria tertentu. $M C D M$ memiliki dua kategori yakni Multiple Objective Decision Making (MODM) dan Multiple Attribute Decision Making (MADM).

Multiple Objective Decision Making (MODM) adalah suatu metode dengan mengambil banyak kriteria sebagai dasar dari pengambilan keputusan yang didalamnya mencakup masalah perancangan (design), dimana teknik matematik untuk optimasi digunakan dan untuk jumlah alternatif yang sangat besar (sampai dengan tak terhingga). Sedangkan Multiple Attribute Decision Making (MADM) adalah suatu metode dengan mengambil banyak kriteria sebagai dasar pengambilan keputusan, dengan penilaian yang subjektif menyangkut masalah pemilihan, dimana analisis matematis tidak terlalu banyak dan digunakan untuk pemilihan alternatif dalam jumlah sedikit. Beberapa teknik dari

Multiple Attribute Decision Making (MADM) seperti AHP (Analytical Hierarchy Process), MAUT/MAVT (Multi Attribute Utility Value Theory), Promethee (Preference Ranking Organization Method for Enrichment Evaluation), Electre, Simple Multi Attribute Rating Technique (SMART) dan lainlain.

\section{B. Kegiatan Ekstrakurikuler}

Kegiatan ekstrakurikuler merupakan suatu kegiatan yang berada di luar program yang tertulis di dalam kurikulum seperti latihan kepemimpinan dan pembinaan siswa. Kegiatan ini memberikan keleluasaan waktu dan memberikan kebebasan pada siswa, terutama dalam menentukan jenis kegiatan yang sesuai dengan minat mereka sendiri. Kegiatan ekstrakurikuler dilaksanakan diluar jam pelajaran wajib pada siswa.

Kegiatan ekstrakurikuler merupakan suatu bagian internal dari proses belajar yang menekankan pada pemenuhan kebutuhan siswa. Kegiatan ekstrakurikuler tidak dapat dipisahkan dari kegiatan intrakulikuler karena kegiatan ekstrakurikuler merupakan pelengkap dari kegiatan intrakulikuler. Kegiatan ekstrakurikuler dapat menjadi sarana untuk menyalurkan bakat atau pendorong perkembangan potensi anak didik mencapai taraf maksimum.

Tujuan dari kegiatan ekstrakurikuler berdasarkan Departemen Pendidikan dan Kebudayaan (1995) dalam Berbagi Ilmu (2016) adalah :

1. Siswa dapat memperdalam dan memperluas pengetahuan dan keterampilan mengenai hubungan antara berbagai mata pelajaran, menyalurkan bakat dan minat.

2. Siswa mampu memanfaatkan pendidikan kepribadiaan serta mengaitkan pengetahuan yang diperolehnya dalam program kurikulum dengan kebutuhan dan keadaan lingkungan.

\section{Sistem Pendukung Keputusan}

Sistem Pendukung Keputusan (SPK) atau Decision Support System (DSS) adalah sebuah sistem yang mampu memberikan kemampuan pemecahan masalah maupun kemampuan pengkomunikasian untuk masalah dengan kondisi semi terstruktur dan tak terstruktur. Sistem ini digunakan untuk membantu pengambilan keputusan dalam situasi semi terstruktur dan situasi yang tidak terstruktur, dimana tak seorangpun tahu secara pasti bagaimana keputusan seharusnya dibuat. (Turban,"Decision Support System and Intelligent Systems", Andi, 2005).

SPK bertujuan untuk menyediakan infomasi, membimbing, memberikan prediksi serta mengarahkan kepada pengguna informasi agar dapat melakukan pengambilan keputusan dengan lebih baik. Dapat juga dikatakan sebagai sistem komputer yang mengolah data menjadi informasi untuk mengambil keputusan dari masalah semi-terstruktur yang spesifik. 
Tahapan dari Sistem Pendukung Keputusan adalah sebagai berikut:

1. Definisi masalah

2. Pengumpulan data atau elemen informasi yang relevan

3. Pengolahan data menjadi informasi baik dalam bentuk laporan grafik maupun tulisan menentukan alternatif-alternatif solusi (bisa dalam persentase)

Tujuan dari Sistem Pendukung Keputusan:

1. Membantu menyelesaikan masalah semi-terstruktur

2. Mendukung manajer dalam mengambil keputusan suatu masalah

3. Meningkatkan efektifitas bukan efisiensi pengambilan keputusan

Dalam pemrosesannya, SPK dapat menggunakan bantuan dari sistem lain seperti Artificial Intelligence, Expert Systems, Fuzzy Logic, dan lain-lain.

\section{Metode SMART}

Metode Simple Multi Attribute Rating Technique merupakan suatu metode untuk pengambilan keputusan muti kriteria yang dikembangkan pada tahun 1997 oleh Edward. Metode SMART didasarkan pada teori bahwa setiap alternatif terdiri dari sejumlah kriteria yang memiliki nilai dan setiap kriteria memiliki bobot yang menggambarkan seberapa penting nilai dari bobot tersebut dibandingkan dengan kriteria lain.

Metode SMART lebih sering digunakan karena kesederhanaannya dalam merespon kebutuhan pembuat keputusan dan menganalisa respon. SMART menggunakan linear additive model untuk meramal nilai setiap alternatif dan metode pengambilan keputusannya fleksibel. Metode ini memberikan pemahaman masalah yang tinggi dan dapat diterima oleh pembuat keputusan.

Adapun langkah-langkah yang dilakukan dalam perumusan metode SMART pada studi kasus pemilihan kegiatan ekstrakurikuler ini adalah sebagai berikut :

a. Menentukan Kriteria apa yang dapat dipakai untuk studi kasus pemilihan kegiatan ekstrakurikuler. Kriteria yang digunakan adalah minat, bakat, pengalaman, dan prestasi.

b. Menentukan alternatif yang akan digunakan. Pada studi kasus ini alternatif yang digunakan adalah semua ekstrakurikuler yang ada di SMA Santa Maria yang dikategorikan menjadi beberapa kategori seperti olahraga, seni, atletik dan lainnya.

c. Memberikan Bobot pada setiap alternatif dengan rumus sebagai berikut :

$u i(a i)=\frac{\text { Cout }- \text { Cmin }}{\text { Cmax }- \text { Cmin }}$

Dimana :

$u i(a i)=$ nilai utility kriteria ke-1 untuk kriteria ke-i

Cout = nilai kriteria ke-1

Cmin = nilai kriteria minimal

$\mathrm{Cmax}=$ nilai kriteria maksimal

d. Hitung nilai normalisasi pada setiap kriteria disetiap alternatif

Normalisasi $=\frac{W_{j}^{j}}{\sum w j}$.

Dimana :

Normalisasi $=$ Nilai bobot kriteria baris i kolom ke $\mathrm{j}$

$\mathrm{Wj}=$ bobot kriteria pada baris $\mathrm{i}$ kolom ke $\mathrm{j}$

$\sum w j=$ Total bobot kriteria pada baris $\mathrm{i}$ kolom ke $\mathrm{j}$

e. Hitung Nilai Utility pada setiap alternatif

$u(a i)=\sum_{j=1}^{m}$ wj ui(ai), $i=1,2, \ldots \mathrm{m}$......(3)

Dimana :

$\mathrm{Wj} \quad=$ nilai pembobotan kriteria ke-j dan $\mathrm{k}$ kriteria

$u i(a i)=$ nilai utility kriteria ke-i untuk kriteria ke-i

Sistem Pendukung Keputusan Pemilihan Kegiatan Ektrskurikuler untuk siswa SMA Menggunkan Metode Simple Multi Attribute Rating Technique (Studi Kasus: SMA Santa Maria )-( Septian Galuh Andika,Kusnadi,Petrus Sokibi) 
f. Lakukan perangkingan berdasarkan nilai utility

g. Pilih Alternatif dengan nilai utility terbesar

Contoh Perhitungan Manual SMART :

1. Tabel 1 berisikan kriteria yang akan digunakan, dalam kasus ini menggunakan 4 kriteria maka digunakan $\mathrm{k} 1, \mathrm{k} 2, \mathrm{k} 3, \mathrm{k} 4$

Tabel 1. Tabel Kriteria

\begin{tabular}{|c|c|}
\hline No & Kriteria \\
\hline 1 & $\mathrm{k} 1$ \\
\hline 2 & $\mathrm{k} 2$ \\
\hline 3 & $\mathrm{k} 3$ \\
\hline 4 & $\mathrm{k} 4$ \\
\hline
\end{tabular}

2. Tabel 2 berisikan contoh pengisian yang sudah dilakukan oleh salah satu siswa maka akan menghasilkan seperti tabel dibawah

Tabel 2. Tabel Pengisian

\begin{tabular}{|l|l|l|l|l|}
\hline \multirow{2}{*}{ Alternatif } & \multicolumn{4}{|c|}{ Kriteria } \\
\cline { 2 - 5 } & minat(k1) & bakat(k2) & pengalaman(k3) & prestasi(k4) \\
\hline \multirow{2}{*}{ Basket } & Tinggi & Berbakat & Sangat Berpengalaman & $\begin{array}{l}\text { Pernah } \\
\text { Juara }\end{array}$ \\
\hline Voli & sangat tinggi & Cukup & Punya Pengalaman & Baru Ikut \\
\hline Futsal & Kurang & kurang berbakat & Cukup Pengalaman & $\begin{array}{l}\text { Hampir } \\
\text { Juara }\end{array}$ \\
\hline & & & & \\
Badminton & Cukup & sangat berbakat & Kurang Pengalaman & Belajaran \\
\hline
\end{tabular}

3. Tabel 3 berisikan bobot dari setiap masing-masing kriteria

Tabel 3. Tabel Bobot

\begin{tabular}{|l|c|c|}
\hline No & Kriteria & Bobot (wj) \\
\hline 1 & $\mathrm{k} 1$ & 40 \\
\hline 2 & $\mathrm{k} 2$ & 30 \\
\hline 3 & $\mathrm{k} 3$ & 20 \\
\hline 4 & $\mathrm{k} 4$ & 10 \\
\hline \multicolumn{2}{|c|}{ Total wj } & 100 \\
\hline
\end{tabular}


4. Tabel 4 berisikan perhitungan normalisasi, Perhitungan Normalisasi digunakan untuk masing-masing kriteria dan diperoleh dari bobot dibagi total bobot(WJ/total WJ)

Tabel 4. Tabel Normalisasi

\begin{tabular}{|c|c|c|c|}
\hline No & Kriteria & Bobot (wj) & $\begin{array}{c}\text { Normalisasi } \\
(w j / t o t a l ~ w j)\end{array}$ \\
\hline 1 & $\mathrm{k} 1$ & 40 & 0,4 \\
\hline 2 & $\mathrm{k} 2$ & 30 & 0,3 \\
\hline 3 & $\mathrm{k} 3$ & 20 & 0,2 \\
\hline 4 & $\mathrm{k} 4$ & 10 & 0,1 \\
\hline
\end{tabular}

5. Tabel 5 berisikan parameter, parameter ditetapkan sesuai dengan jumlah kriteria yang ada untuk kasus ini digunakan 4 kriteria sehingga diperoleh 4 parameter

Tabel 5. Tabel Parameter

\begin{tabular}{|l|r|}
\hline sangat baik & 1 \\
\hline Baik & 2 \\
\hline Cukup & 3 \\
\hline kurang baik & 4 \\
\hline
\end{tabular}

6. Tabel 6 berisikan parameter dari masing-masing kriteria, nilai value didapatkan dari tabel 5 berisikan nilai dari 1 hingga 4

7.

\section{Tabel 6. Tabel Value}

\begin{tabular}{|c|c|l|c|}
\hline No & Kriteria & Parameter & Value \\
\hline 1 & \multirow{3}{*}{$\mathrm{k} 1$} & sangat tinggi & 1 \\
\cline { 3 - 4 } & & Tinggi & 2 \\
\cline { 3 - 4 } & & Cukup & 3 \\
\cline { 3 - 4 } & & Kurang & 4 \\
\hline \multirow{3}{*}{2} & \multirow{3}{*}{$\mathrm{k} 2$} & sangat berbakat & 1 \\
\cline { 3 - 4 } & & Berbakat & 2 \\
\cline { 3 - 4 } & & Cukup & 3 \\
\cline { 3 - 4 } 3 & \multirow{3}{*}{$\mathrm{k} 3$} & $\begin{array}{l}\text { kurang } \\
\text { berbakat }\end{array}$ & 4 \\
\hline & & $\begin{array}{l}\text { Sangat } \\
\text { Berpengalaman }\end{array}$ & 1 \\
\cline { 3 - 4 } & & $\begin{array}{l}\text { Punya } \\
\text { Pengalaman }\end{array}$ & 2 \\
\hline
\end{tabular}

Sistem Pendukung Keputusan Pemilihan Kegiatan Ektrskurikuler untuk siswa SMA Menggunkan Metode Simple Multi Attribute Rating Technique (Studi Kasus: SMA Santa Maria )-( Septian Galuh 


\begin{tabular}{|l|l|l|c|}
\hline \multirow{4}{*}{4} & $\begin{array}{l}\text { Cukup } \\
\text { Pengalaman }\end{array}$ & 3 \\
\cline { 3 - 4 } & Kurang & \\
& Pengalaman & 4 \\
\hline \multirow{4}{*}{$\mathrm{k} 4$} & Pernah Juara & 1 \\
\cline { 3 - 4 } & Hampir Juara & 2 \\
\cline { 3 - 4 } & & Belajaran & 3 \\
\cline { 3 - 4 } & Baru Ikut & 4 \\
\hline
\end{tabular}

8. Tabel 7 berisikan nilai utility dari setiap alternatif yang terdiri dari setiap kriteria, nilai utility didapat dari parameter yang sudah terdapat dalam tabel 6 , Menentukan nilai utility didasarkan pada

Tabel 7. Tabel Utility

\begin{tabular}{|l|c|c|c|c|}
\hline Kriteria & \multirow{2}{*}{$\mathrm{k} 1$} & $\mathrm{k} 2$ & $\mathrm{k} 3$ & $\mathrm{k} 4$ \\
\cline { 1 - 2 } Alternatif & & 2 & 1 & 1 \\
\hline $\mathrm{y} 1$ & 2 & 3 & 2 & 3 \\
\hline $\mathrm{a} 2$ & 4 & 4 & 3 & 2 \\
\hline $\mathrm{a} 3$ & 3 & 1 & 4 & 4 \\
\hline $\mathrm{y} 4$ & &
\end{tabular}

9. Tabel 8 berisikan perhitungan akhir pada metode smart untuk menentukan manakah kegiatan yang terpilih, Nilai utility didapatkan dari (Cout-Cmin)/(Cmax-Cmin), Cout adalah nilai yang terdapat pada tabel 7 yang didapat dari parameter dari tabel 2, Bobot normalisasi didapatkan dari tabel 4, Skor diperoleh dari (nilai utility k1 dikali bobot normalisasi k1)+(nilai utility $\mathrm{k} 2$ dikali bobot normalisasi k2 dan seterusnya hingga $\mathrm{k} 4$ maka diperolehlah skor, Untuk pernyataan adalah keterangan manakah alternatif yang memiliki skor terbesar maka merupakan pilihan utama

Tabel 8. Tabel Penilaian

\begin{tabular}{|c|c|c|c|c|c|c|}
\hline no & Alternatif & Kriteria & nilai utility & bobot normalisasi & Skor & Pernyataan \\
\hline \multirow{4}{*}{1} & \multirow{4}{*}{ a1 } & $\mathrm{k} 1$ & 0,33 & 0,4 & \multirow{4}{*}{0,37} & \multirow{4}{*}{3} \\
\hline & & $\mathrm{k} 2$ & 0,33 & 0,3 & & \\
\hline & & $\mathrm{k} 3$ & 0,67 & 0,2 & & \\
\hline & & $\mathrm{k} 4$ & 0,00 & 0,1 & & \\
\hline \multirow{4}{*}{2} & \multirow{4}{*}{ a2 } & $\mathrm{k} 1$ & 0,00 & 0,4 & \multirow{4}{*}{0,23} & \multirow{4}{*}{4} \\
\hline & & $\mathrm{k} 2$ & 0,67 & 0,3 & & \\
\hline & & $\mathrm{k} 3$ & 0,00 & 0,2 & & \\
\hline & & $\mathrm{k} 4$ & 0,33 & 0,1 & & \\
\hline
\end{tabular}




\begin{tabular}{|c|c|c|c|c|c|c|}
\hline \multirow{4}{*}{3} & \multirow{4}{*}{ a3 } & $\mathrm{k} 1$ & 1 & 0,4 & \multirow{4}{*}{0,77} & \multirow{4}{*}{1} \\
\hline & & $\mathrm{k} 2$ & 1 & 0,3 & & \\
\hline & & $\mathrm{k} 3$ & 0,33 & 0,2 & & \\
\hline & & $\mathrm{k} 4$ & 0,00 & 0,1 & & \\
\hline \multirow{4}{*}{4} & \multirow{4}{*}{$\mathrm{a} 4$} & $\mathrm{k} 1$ & 0,67 & 0,4 & \multirow{4}{*}{0,53} & \multirow{4}{*}{2} \\
\hline & & k2 & 0,00 & 0,3 & & \\
\hline & & k3 & 1 & 0,2 & & \\
\hline & & $\mathrm{k} 4$ & 0,67 & 0,1 & & \\
\hline
\end{tabular}

\section{Hasil dan Pembahasan}

\section{A. Antar Muka Sistem}

Sistem Pendukung Keputusan Pemilihan Kegiatan Ekstrakurikuler dengan Metode SMART Berbasis Web (Studi Kasus : SMA Santa Maria Cirebon) telah dibangun dengan menggunakan bahasa pemrograman PHP dan database MySQL. Adapun pengguna sistem ini dibagi menjadi 2, yaitu siswa atau user biasa yang dapat mengakses menu Pemilihan Kegiatan Ekstrakurikuler dan Biodata Siswa dan Bagian Kesiswaan yang dapat mengakses semua menu.

\section{Halaman Beranda Siswa}

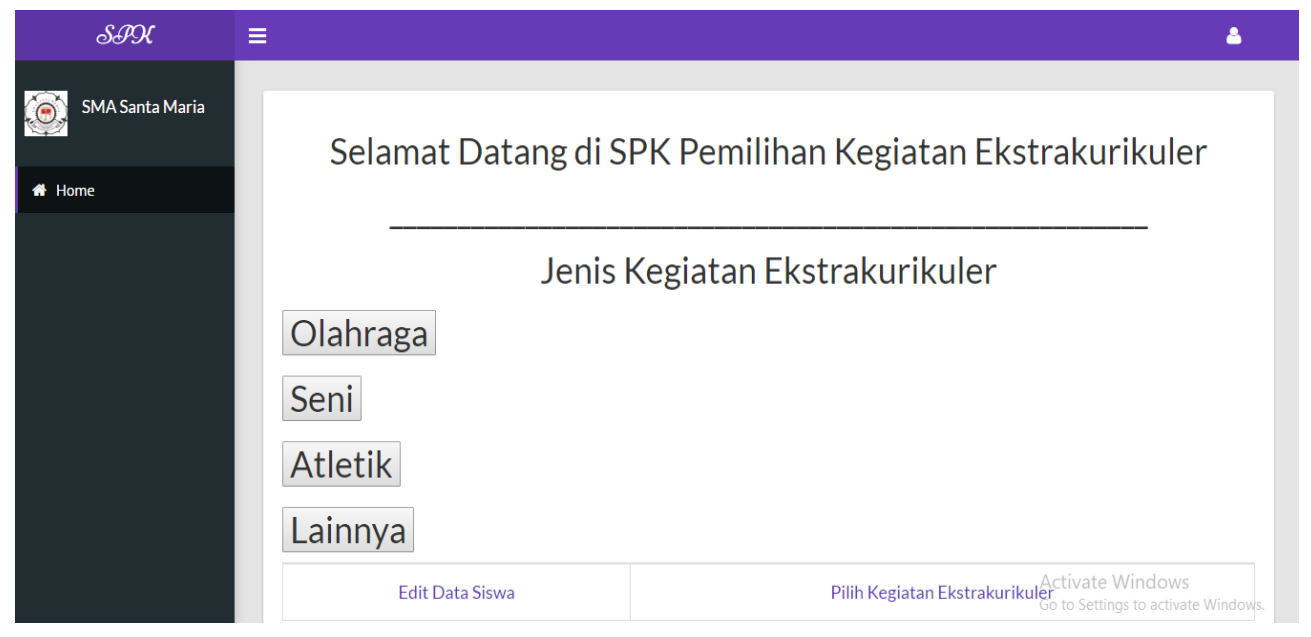

Gambar 1. Halaman Beranda Siswa

\section{Halaman Kriteria}




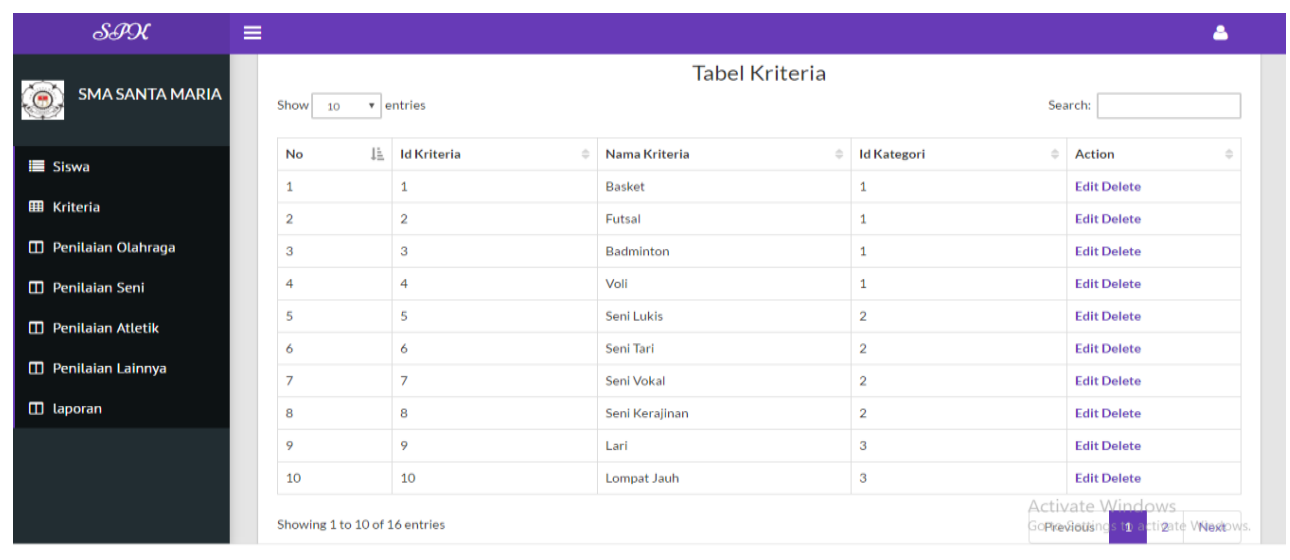

Gambar 2. Halaman Kriteria

3. Halaman Data Siswa

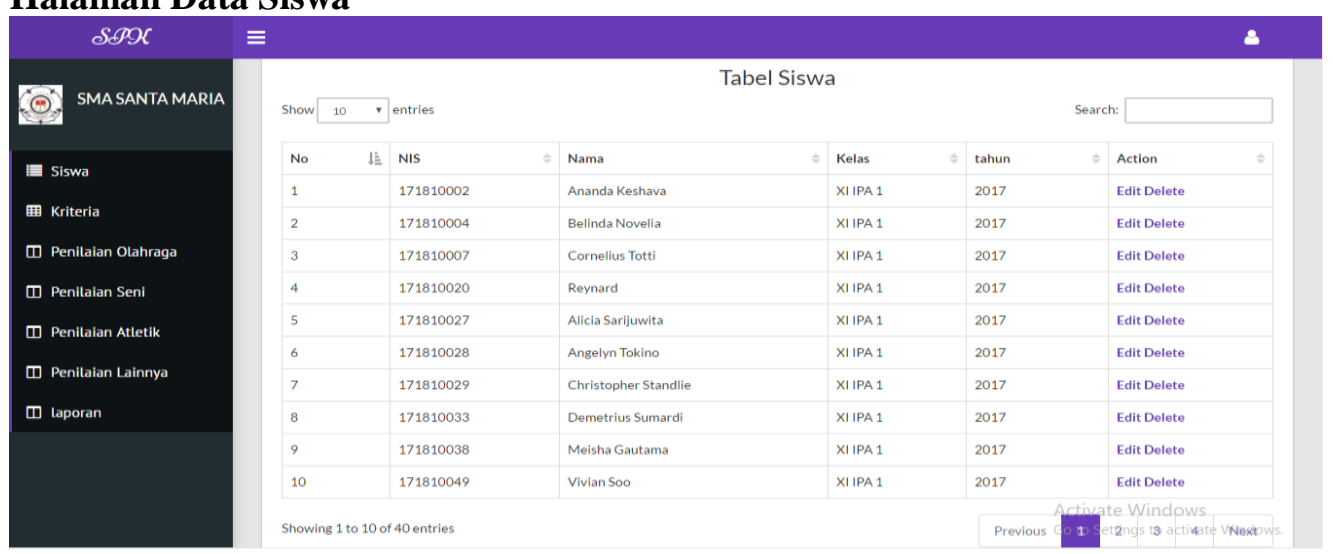

Gambar 3. Halaman Data Siswa

4. Halaman Penilaian Olahraga

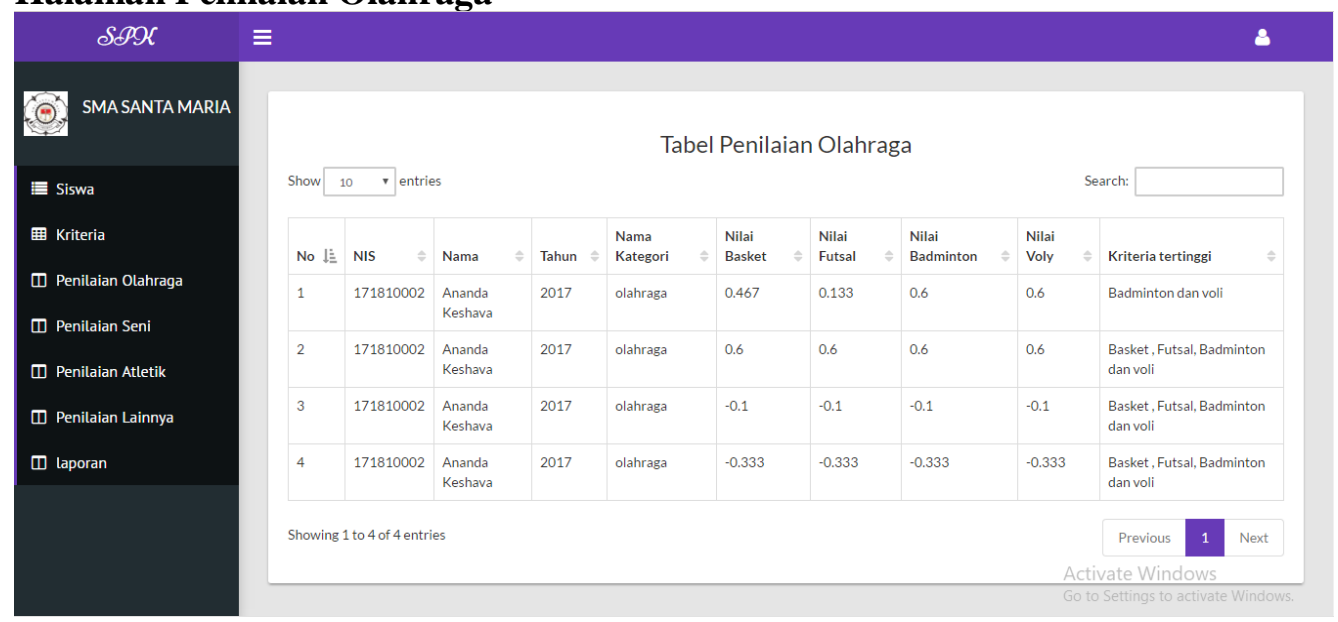

Gambar 4. Halaman Penilaian Olahraga 
5. Halaman Penilaian Seni

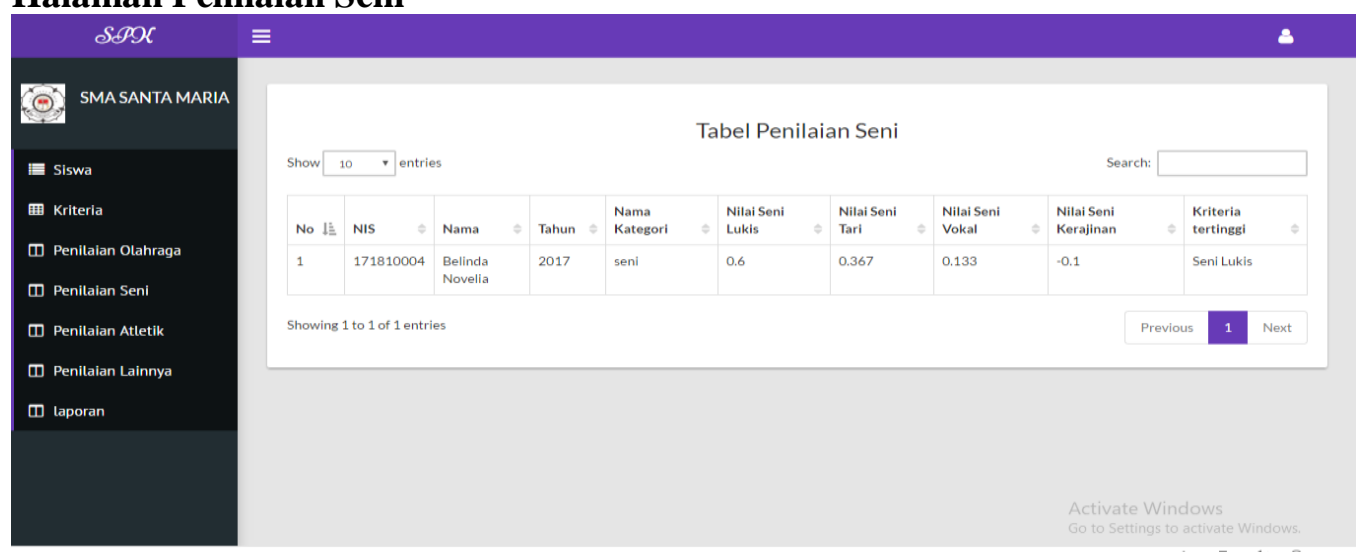

Gambar 5. Halaman Penilaian Seni

6. Halaman Penilaian Atletik

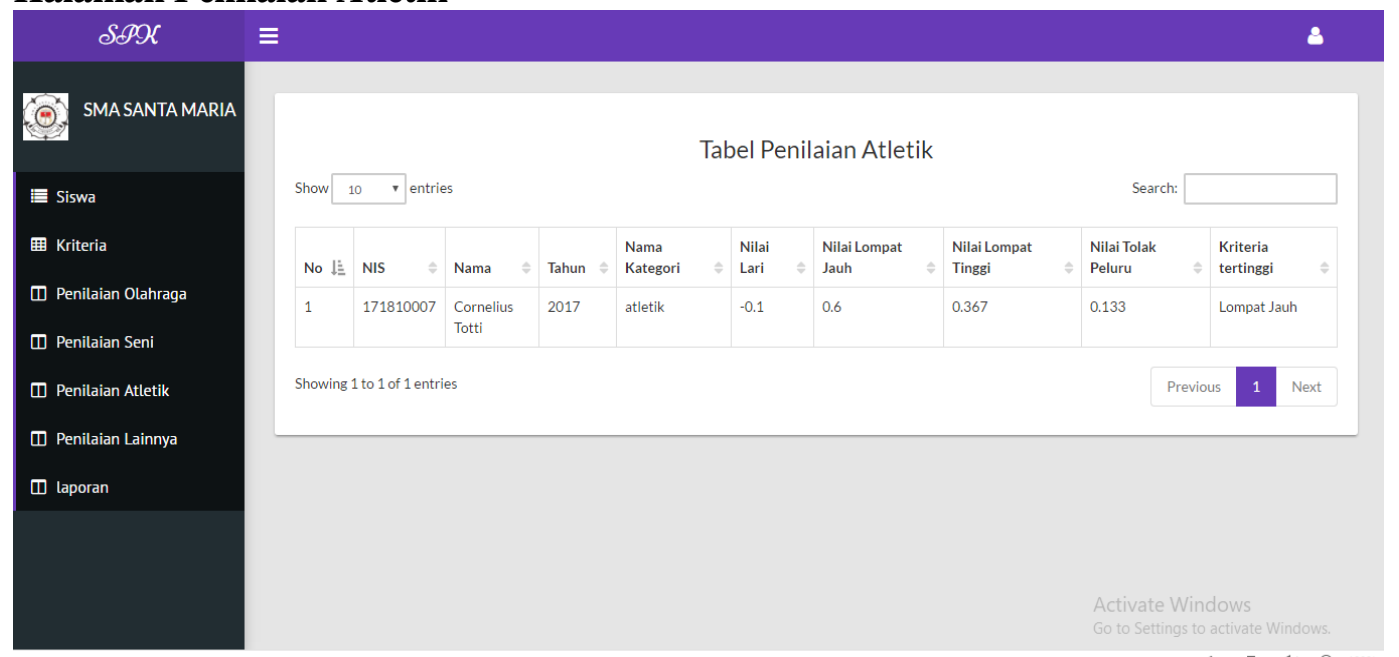

Gambar 6. Halaman Penilaian Atletik

7. Halaman Penilaian Lainnya

Sistem Pendukung Keputusan Pemilihan Kegiatan Ektrskurikuler untuk siswa SMA Menggunkan Metode Simple Multi Attribute Rating Technique (Studi Kasus: SMA Santa Maria )-( Septian Galuh Andika,Kusnadi,Petrus Sokibi) 


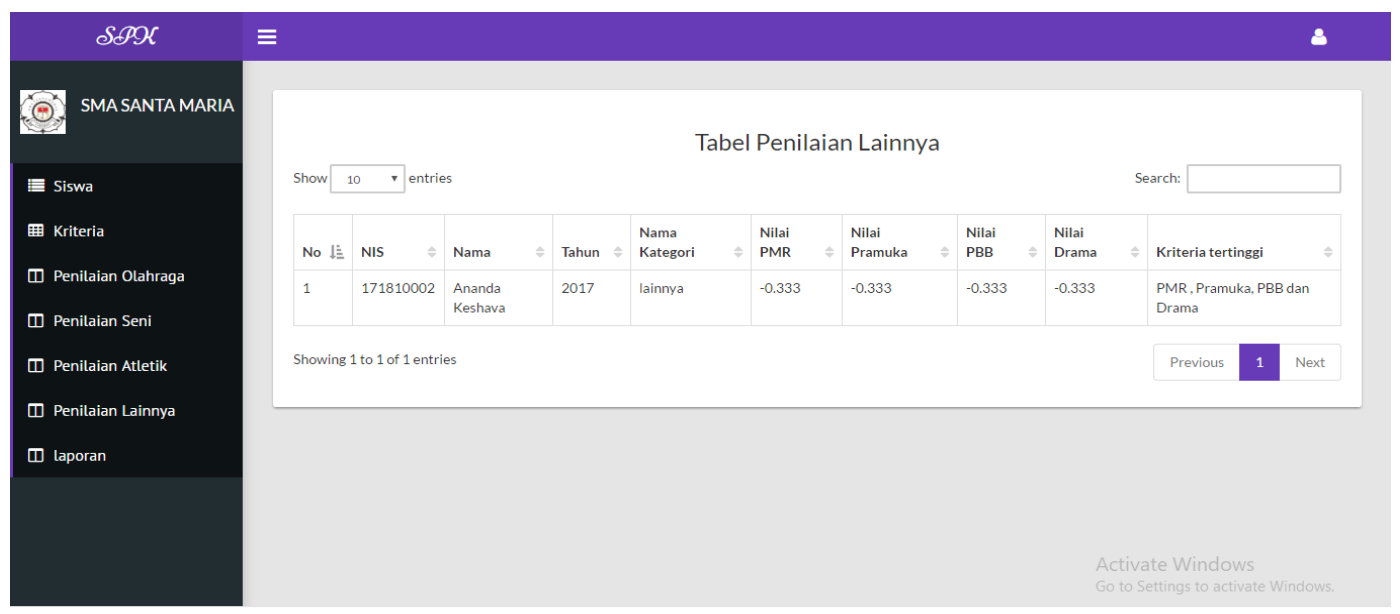

Gambar 7. Halaman Penilaian Lainnya

8. Halaman Laporan

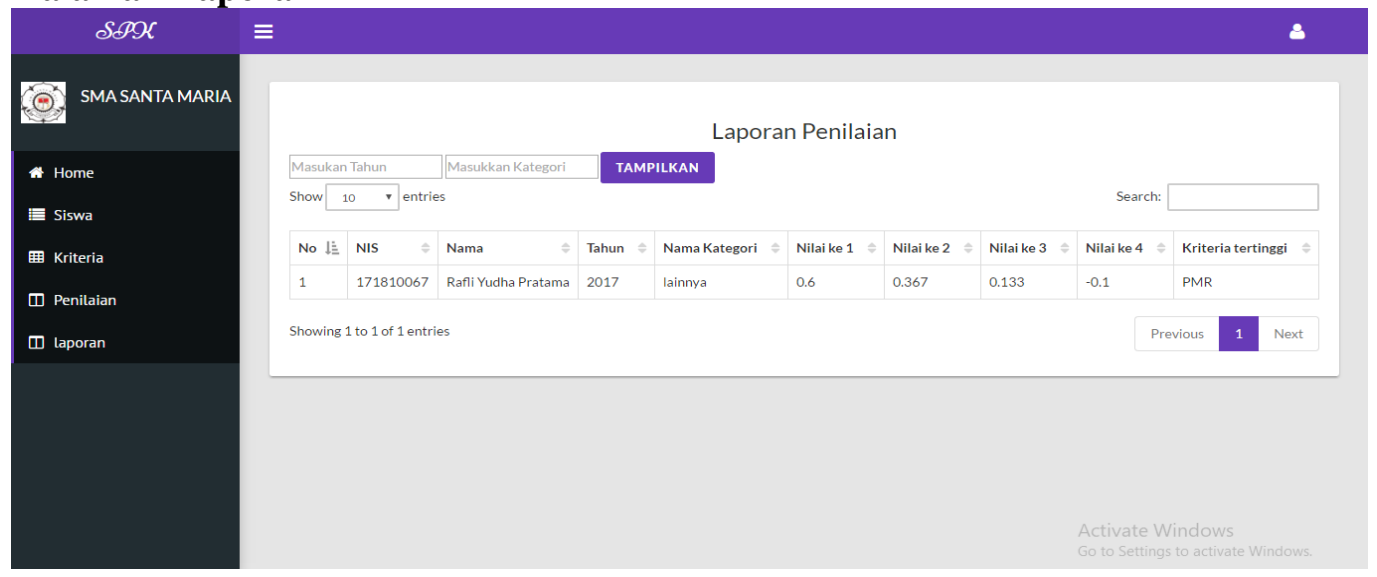

4. Pengujian Sistem

Gambar 8. Halaman Laporan

\section{Pengujian Black Box}

Pengujian pada sistem ini dilkukan dengan menggunakan Black Box Testing.

Pengujian black box ini dilakukan dengan menguji setiap fungsi pada sistem apakah telah bekerja dengan baik atau belum

\section{Kesimpulan}

\section{A. Kesimpulan}

Setelah pembuatan Sistem Pendukung Keputusan Pemilihan Kegiatan Ekstrakurikuler untuk siswa SMA menggunakan metode simple multi attribute rating technique(smart), maka dapat disimpulkan antara lain sebagai berikut :

1. Hasil Pemilihan Kegiatan Ekstrakurikuler didapat berdasarkan minat, bakat, pengalaman, dan prestasi siswa

2. Aplikasi ini dapat digunakan tidak hanya di lingkungan sekolah namun pengumpulan data dapat terkumpul secara terorganisir.

3. Aplikasi ini membantu persentase pengembalian data siswa lebih tinggi dibandingkan menggunakan formulir.

4. Aplikasi ini dibuat menggunakan bahasa pemograman PHP dan menggunakan databse MYSQL 
berbasis web.

5. Aplikasi ini dibuat berdasarkan kriteria dan alternatif yang sudah ditentukan, kriteria yang digunakan dibuat berdasarkan penilaian terhadap diri sendiri(siswa) sehingga aplikasi ini dapat membantu siswa dalam memilih kegiatan ekstrakurikuler secara tepat.

\section{B. Saran}

Dalam penyusunan skripsi teknik informatika ini,penulis menyadari masih banyak terdapat kekurangan dalam aplikasi ini. Adapun saran-saran yang dapat saya berikan adalah dengan menambahkan beberapa fitur seperti :

1. Membuat aplikasi berbasis android

2. Menambahkan fitur data peserta masing-masing ekstrakurikuler

3. Membuat kriteria berdasarkan masukan dari guru bersangkutan

4. Menambahkan fitur siswa dapat memilih lebih dari 1 pilihan

5. Menambahkan fitur batasan bagi siswa dalam memilih sesuai aturan yang berlaku

\section{Daftar Pustaka}

[1] Jeffery L. Whitten., Metode Desain dan Analisa Sistem, ANDI, Yogyakarta, 2004

[2] Jogiyanto, H.M., Pengenalan Komputer: Dasar Ilmu Komputer, Pemrograman, Sistem Informasi, Informaka, Bandung, 1999

[3] Komponen Class Diagram pada BAB II, dapat diakses pada tanggal 1 februari 2019 (http://sis.binus.ac.id/2016/06/20/domain-class-diagram/)

[4] Komponen Sequence Diagram pada BAB II, dapat diakses pada tanggal 1 februari 2019 (http://share.its.ac.id)

[5] Magrisa, Tisa.,Implementasi Metode Smart pada Sistem Pendukung Keputusan Pemilihan Kegiatan Ekstrakurikuler untuk Siswa SMA， Riau,2018

[6] Multi Criteria Decision Making pada BAB II, dapat diakses pada tanggal 15 Januari 2019 (ejournal.uajy.ac.id/1674/3/2TI05111.pdf)

[7] Pengambilan Keputusan Multi Kriteria pada BAB II, dapat diakses pada tanggal 15 Januari 2019(Google Terjemahan > https://en.wikipedia.org/wiki/Multiple-criteria decision analysis)

[8] Pengertian Alternatif pada BAB II, dapat diakses pada tanggal 15 januari 2019(https://kbbi.web.id/alternatif)

[9] Pengertian Alternatif pada BAB II, dapat diakses pada tanggal 1 februari 2019(http://www.pengertianmenurutparaahli.net/pengertian-alternatif-pemecahan-masalah/)

[10] Pengertian Kegiatan Ekstrakurikuler pada BAB II, dapat diakses pada 15 Januari 2019(ejournals.unmul.ac.id/index.php/JIM/article/view/648)

[11] Pengertian Kriteria pada BAB II, dapat diakses pada tanggal 15 januari 2019 (https://kbbi.web.id/kriteria)

[12] Pengertian Kriteria pada BAB II, dapat diakses pada tanggal 15 januari 2019(http://arti-definisipengertian.info/pengertian-kriteria/)

[13] Pengertian Sistem pada BAB II, dapat diakses pada tanggal 15 Januari 2019 (https://id.wikipedia.org/wiki/Sistem)

[14] Rafiudin, Rahmat., E-News Publishing Panduan Bagi Webmaster, Cyber Media, 2004

[15] Sidik, Betha Ir. MySQL Untuk Pengguna, Administrator dan Pengembang Aplikasi Web, Informatika, Bandung, 2003

[16] Sistem Pendukung Keputusan pada BAB II, dapat diakses pada tanggal 15 Januari 2019(https://id.wikipedia.org/wiki/Sistem pendukung keputusan)

[17] Supono, dkk., Pemrograman Web dengan Menggunakan PHP dan Framework Codeigniter, Deepublish, Yogyakarta, 2016

[18] Susanto, Azhar., Sistem Informasi Manajemen, Linggar Jaya, Bandung, 2004

[19] Turban,"Decision Support System and Intelligent Systems", ANDI, Yogyakarta, 2005 
JURNAL DIGIT Vol. 9, No.1 Mei 2019, pp.59 70

ISSN : 2088-589X 